\title{
(Re)Aprendendo com as crianças no espaço-tempo da escola
}

Grazielle Eloísa Balduino', Myrtes Dias da Cunha²

\section{Resumo}

Pode a educação escolar ser significativa para as crianças nos dias de hoje? $O$ que podemos aprender com as crianças sobre o ensinar-aprender na escola? O presente trabalho pretendeu conhecer modos de envolvimento das crianças entre si, com os conteúdos escolares e com o conhecimento no âmbito da escola. Propomo-nos a analisar atividades escolares de matemática, desenvolvidas em sala de aula com alunos do terceiro ano do ensino fundamental de uma escola municipal de Uberlândia, em Minas Gerais, análise realizada no âmbito de uma pesquisa maior em andamento que envolve conhecer e trabalhar com culturas infantis. A primeira atividade apresentada às crianças consistiu em resolver problemas matemáticos, envolvendo a soma e a subtração; a segunda, na realização de um bingo contendo tais operações. Verificamos que produzir com as crianças, ao invés de realizarmos atividades planejadas para elas, nos permitiu compreender melhor seus interesses, possibilidades, jeitos de aprender, modos de interagir e de produzir algo próprio, com destaque para o fato de que as crianças são sujeitos criativos que ressignificam o conhecimento e transformam as atividades propostas e, assim, nos ensinam sobre como podem aprender.

\section{Palavras-chave}

Infâncias. Cotidiano Escolar. Educação Matemática. EnsinarAprender.

1. Mestranda em Educação pela Universidade Federal de Uberlândia. E-mail: balduino.grazielle@gmail.com.

2. Doutora em Educação pela Universidade Estadual de Campinas, professora associada na Faculdade de Educação da Universidade Federal de Uberlândia. E-mail: myrtesufu@gmail.com. 


\title{
Relearn process with children at school's place-time
}

\author{
Grazielle Eloísa Balduino*, Myrtes Dias da Cunha**
}

\begin{abstract}
Nowadays, can education of school be really important to children? How is it possible? What we can learn about learning-teaching process with children at school? This current study sought to know about children relationship with themselves, subjects and knowledge concerning the school. With that purpose, in this article, we analyzed math activities developed in a public elementary school with third grade students. These activities take part of a general research about childhood culture. The first activity presented to children consisted of solving addition and subtraction problems; the second one consisted about a bingo involving those operations. Children had more success with bingo. Next, we concluded being necessary to produce knowledge with children, not only for them. We noticed that produce with children, instead of doing planned activities to them, allowed us to figure out better about their interests, possibilities, learning ways producing by themselves and together, and about their interactions possibilities. Emphasizing the fact that children are creative people who rebuild knowledge and transformed the school works; this process teaches professors, researchers, about how we can work together with them and us.
\end{abstract}

\section{Keywords}

Childhood. School Daily Life. Mathematics Education. Learning-Teaching Process.

\footnotetext{
* Candidate for a master's degree in Education at the Federal University of Uberlândia. E-mail: balduino.grazielle@ gmail.com.

** Doctor in Education at the State University of Campinas, associate professor at the Faculty of Education at Federal University of Uberlândia. E-mail: myrtesufu@gmail.com.
} 


\section{Introdução}

Escolhi a sombra desta árvore / Para repousar do muito que farei / Enquanto esperarei por ti / Quem espera na pura espera / Vive um tempo de espera vã / Por isto, enquanto te espero / Trabalharei os campos e / Conversarei com os humanos / Suarei meu corpo, que o sol queimará;/ Minhas mãos ficarão calejadas / Meus pés aprenderão o mistério dos caminhos / Meus ouvidos ouvirão mais / Meus olhos verão o que antes não viam / Enquanto esperarão por ti / Não te esperarei na pura espera / Porque o meu tempo de espera é um / Tempo de quefazer / desconfiarei daqueles que virão dizer-me, / em voz baixa e precavida: / é perigoso agir / é perigoso falar / é perigoso andar / é perigoso esperar, na forma em que esperas / porque esses recusam a alegria de tua chegada / Desconfiarei também daqueles que virão dizer-me / Com palavras fáceis, que já chegaste, / Porque esses, ao anunciar-te ingenuamente, / Antes te denunciam. / Estarei preparando a tua chegada / Como o jardineiro prepara o jardim / Para a rosa que se abrirá na primavera. (FREIRE, 1971).

O que é preciso para que a educação escolar seja significativa para as crianças? O que podemos aprender com as crianças sobre o ensinar-aprender na escola? Várias pesquisas se preocupam em desenvolver ou ressignificar métodos e teorias sobre as práticas educativas com crianças, mas ainda vivenciamos escolas carentes de reestruturação curricular com a predominância de atividades escolares que não são condizentes com a realidade das comunidades, estruturas físicas inadequadas, número excessivo de alunos por sala, ausência de ambientes e equipamentos adequados ao trabalho educativo com crianças, por exemplo, sala de brinquedo, de cinema e de informática.

O presente trabalho está inserido em um projeto mais amplo de pesquisa em andamento e busca entender como se dá o envolvimento das crianças com o aprender, com os conteúdos, com as pessoas, crianças e adultos, no espaço-tempo da escola. Analisamos aqui duas atividades de Matemática desenvolvidas em sala de aula com 30 estudantes de 8 e 9 anos de idade, de um terceiro ano do ensino fundamental em uma escola municipal da cidade de Uberlândia, em Minas Gerais, localizada em uma região na qual a exclusão e a desigualdade sociais são marcas visíveis dos espaços em que vivem tais crianças.

A escolha das atividades de Matemática partiu de opiniões de professoras que trabalhavam em turmas de terceiro ano da escola. Essas professoras apontaram como significativas dificuldades de aprendizado dos alunos com as operações matemáticas fundamentais. Para elaboração da lista de exercícios trabalhada com as crianças, utilizamos como referência um livro didático ${ }^{3}$ do terceiro ano do ensino fundamental e sites da internet ${ }^{4}$. Os critérios de seleção dos exercícios privilegiaram o grau de complexidade de conhecimentos que cada um deles abordava e por conterem adição ou subtração, de acordo com a opinião das professoras.

O trabalho com as crianças consistiu em duas partes. Na primeira, propusemos, no dia 25 de outubro de 2011, que resolvessem uma lista de exercícios composta por nove tarefas, divididas em quatro folhas de papel tipo A2, envolvendo a adição e a subtração. Abaixo apresentamos tais exercícios:

3. IMENES, L. M.; LELLIS, M. Matemática para todos. $3^{a}$ série. São Paulo: Scipione, 2004. (Coleção Paratodos).

4. Blog de Matemática disponível em: <http://www.atividadesdematematica.com/atividade-de-matematicapara-o-3-ano>. Acesso em: 30 out. 2011. 
Figura 1 - Primeira página da lista de exercícios.

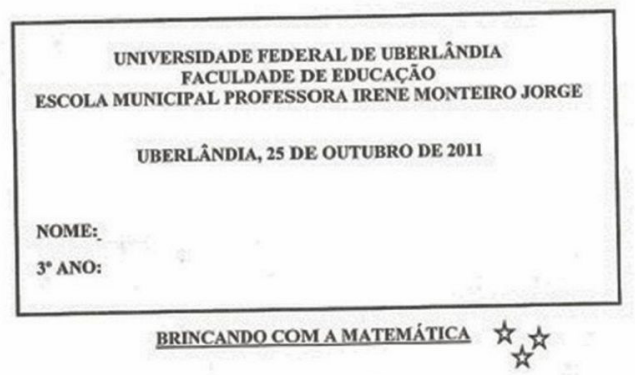

1. João é filho de seu Mateus, que planta feijão e milho. Ele trabalha na roça para ajudar o pai.

Seleciona as sementes de feijão, conta antes de colocar em saquinhos de 20 sementes e leva para semear.

Depois que as sementes brotam, ele conta os pés de feijão.

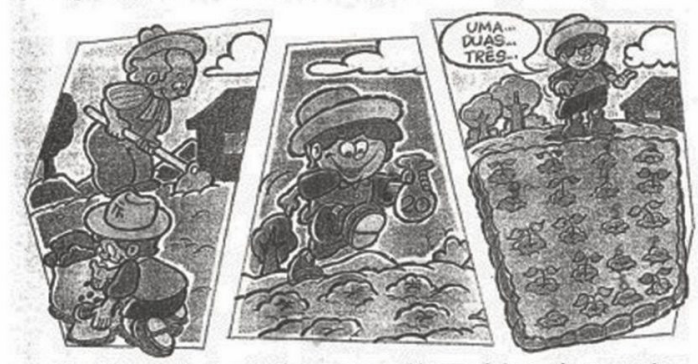

No último plantio, Joăo semeou 10 saquinhos de sementes. Quando foi contar os pés de feijăo que nasceram, viu que apenas 153 pés haviam brotado.

Entăo ele percebe que nem todas as sementes brotaram.

Quantas sementes das que Joăo plantou năo brotaram?

Fonte: Acervo das autoras.
Figura 2 - Segunda página da lista de exercícios.

2) Mateus, Luís, Rita e Carlos sempre brincam

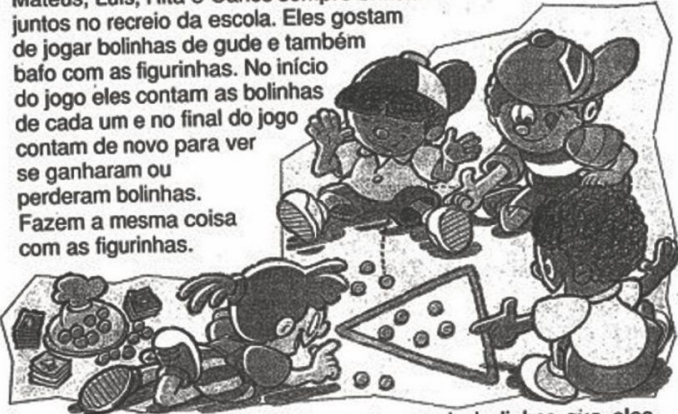

Aqui você tem as tabelas da contagem de bolinhas que eles Aqui voce tem as antes e depois de jogar:

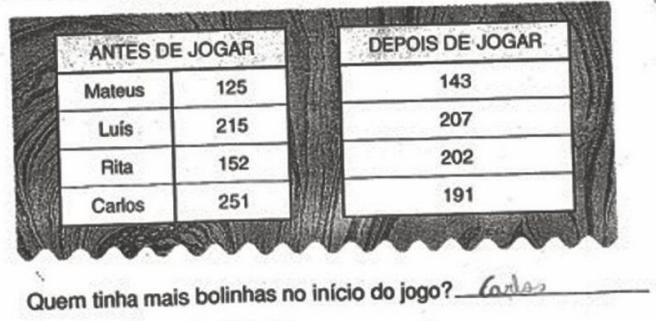

Quem tinha menos? RaTeu

Escreva as quantidades do início do jogo em ordem crescente. 1250151215 inicio

$125,151,215$.
Durante o jogo quem ganhou bolinhas? carlos
Quem perdeu bolinhas? Ma mus do jogo, quem ficou com mais bolinhas? cartas

Qun ficou com menos bolinhas? MoJu

Fonte: Acervo das autoras. 
Figura 3 - Terceira página da lista de exercícios.

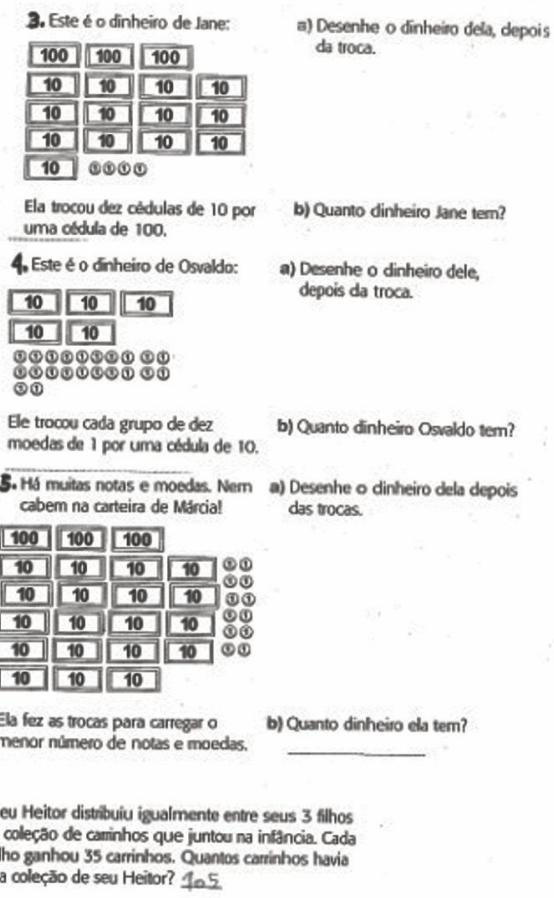

Fonte: Acervo das autoras.

Em relação à resolução dos exercícios que compuseram a lista, percebemos que as crianças mostraram-se interessadas em desenvolver respostas para os problemas apresentados. Elas produziram respostas diferentes, particulares e, a princípio, inesperadas. Por exemplo, uma questão consistiu em colorir as ilustrações apresentadas no primeiro exercício, principalmente a figura do garoto que cuida de uma horta (Figura 1); na Figura 2, a mesma criança respondeu corretamente algumas das perguntas do exercício número 2, por exemplo, qual dos meninos possuía mais e menos bolinhas de gude, além de organizar de forma correta a ordem crescente dos números que expressavam a quantidade de
Figura 4 - Quarta página da lista de exercícios.

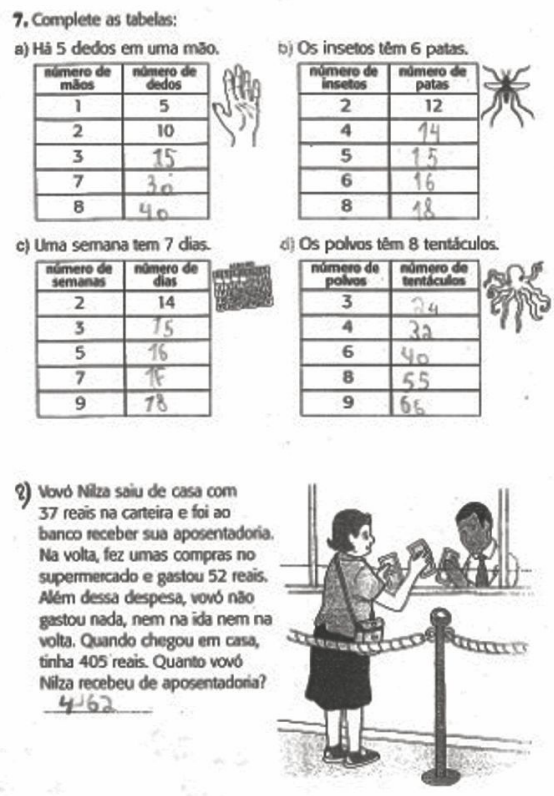

Fonte: Acervo das autoras.

bolinhas de gude no início do jogo. Entretanto, as respostas para as quatro últimas perguntas da segunda folha de exercícios não estavam corretas, logo, precisaríamos entender melhor o porquê de tais respostas. De qualquer maneira, esta criança parece ter compreendido o valor posicional dos algarismos. Observamos que, no momento em que as crianças estavam resolvendo os exercícios, muitas delas demonstraram dificuldade para compreender os enunciados apresentados, o que sinalizou que, para resolver os exercícios, os estudantes devem ser capazes de ler e interpretar enunciados, o que requer, por exemplo, um trabalho conjunto com a disciplina de língua portuguesa. 
Figura 5 - Folha de respostas dos exercícios de K.

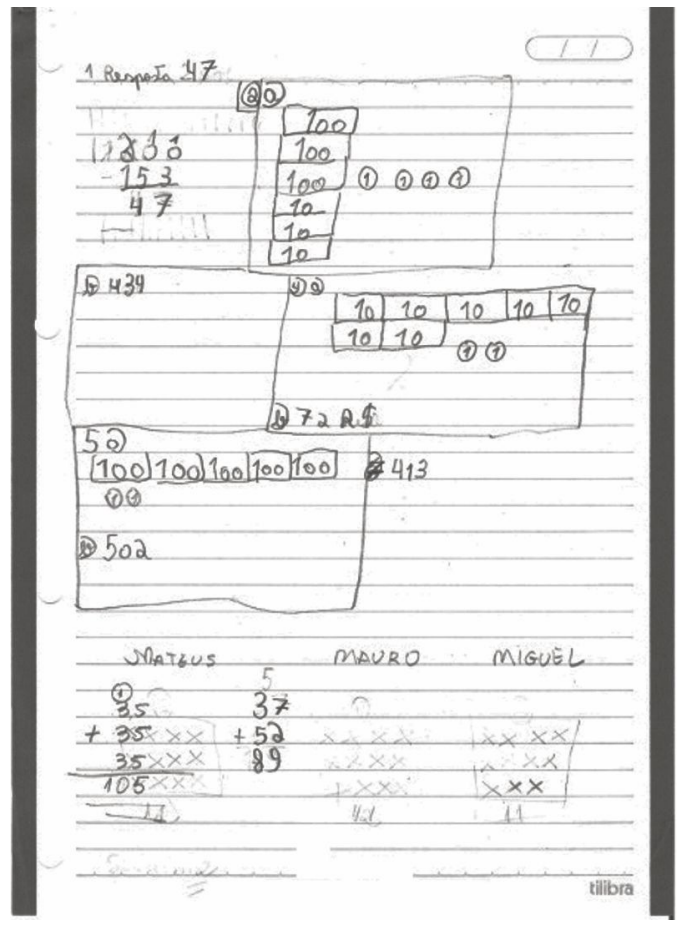

Fonte: Acervo das autoras.

Podemos visualizar respostas construídas por duas crianças nas Figuras 6 e 7 apresentadas. Sabemos que tais tentativas não constituem respostas esperadas para alguns dos exercícios propostos, mas o que mais chamou a nossa atenção, nesse caso, foi o fato de que todas as crianças se envolveram com o trabalho proposto, mesmo os exercícios apresentados sendo distantes dos conteúdos escolares que já haviam aprendido.

No decorrer das ações na escola, o "bom senso" teve uma importância significativa para a nossa pesquisa. Nas avaliações das pesquisadoras, feitas após a realização das atividades com as crianças, o "bom senso" nos ajudou a entender o que foi concretizado e a reconhecer a inadequação do que propuséramos àquelas crianças. Freire diz que o "bom senso" deve nos guiar na avaliação
Figura 6 - Folha de respostas dos exercícios de C.

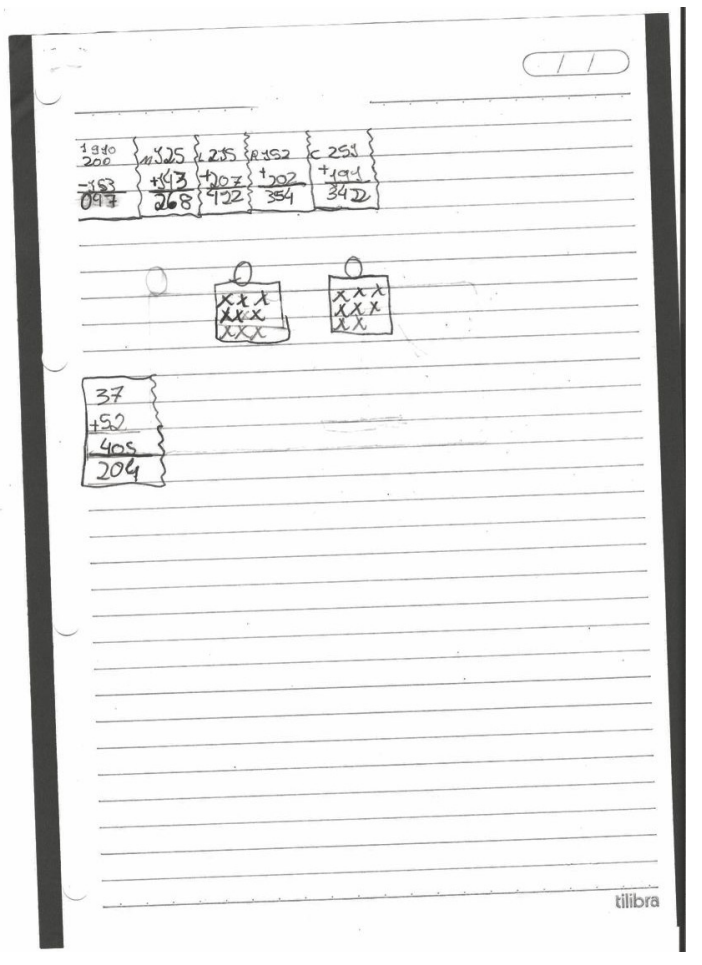

Fonte: Acervo das autoras.

das ações educativas, e completa dizendo:

[...] meu bom senso me diz que devo respeitar a autonomia, a dignidade e a identidade do educando e, na prática, procurar a coerência com este saber, me leva inapelavelmente à criação de algumas virtudes ou qualidades sem as quais aquele saber vira inautêntico, palavreado vazio e inoperante. (FREIRE, 2008, p. 62).

O bom senso indicou-nos o quanto é importante escutar as crianças, principalmente quando percebermos ser necessário alterar o trabalho educativo, por não conseguirmos chegar até elas.

No final da lista de exercícios, na última folha, perguntamos se as crianças haviam gostado de fazer aquela atividade e sobre as facilidades e/ou dificuldades encontradas para 
resolver os problemas. Muitas delas escreveram que encontraram dificuldades para compreender os problemas apresentados e desenvolver as operações necessárias à resolução dos mesmos. Acompanhando a realização do exercício, nós pesquisadoras percebemos tais dificuldades, já que elas também comentaram a respeito disso conosco.

Sobre o fato de todos gostarem de fazer os exercícios de matemática propostos, uma das hipóteses que pode explicar tal avaliação é que as crianças acharam válido o desafio que a atividade representou e que as circunstâncias para realização delas foi motivadora, uma vez que puderam conversar entre si e contar com a atenção das pesquisadoras. Houve casos de crianças que não conseguiram escrever suas respostas de forma inteligível, mas, por tentarem fazer o que foi proposto, valorizamos essas tentativas e a vontade de fazer. Todas as crianças relataram que o trabalho, em geral, foi divertido.

Figuras 7 - Avaliação de K sobre o trabalho com a lista de exercícios.

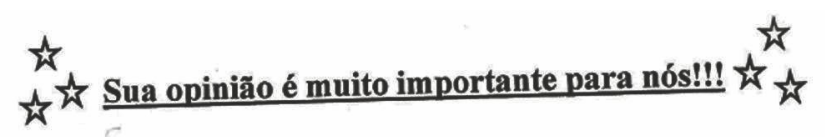

1) Você gostou de fazer essa atividade? Justifique.
$\operatorname{sim}$

2) Quais foram às facilidades e/ou as dificuldades que você encontrou ao realizar essa atividade?

Main una

Fonte: Acervo das autoras. 
Figura 8 - Avaliação de C sobre o trabalho com a lista de exercícios.
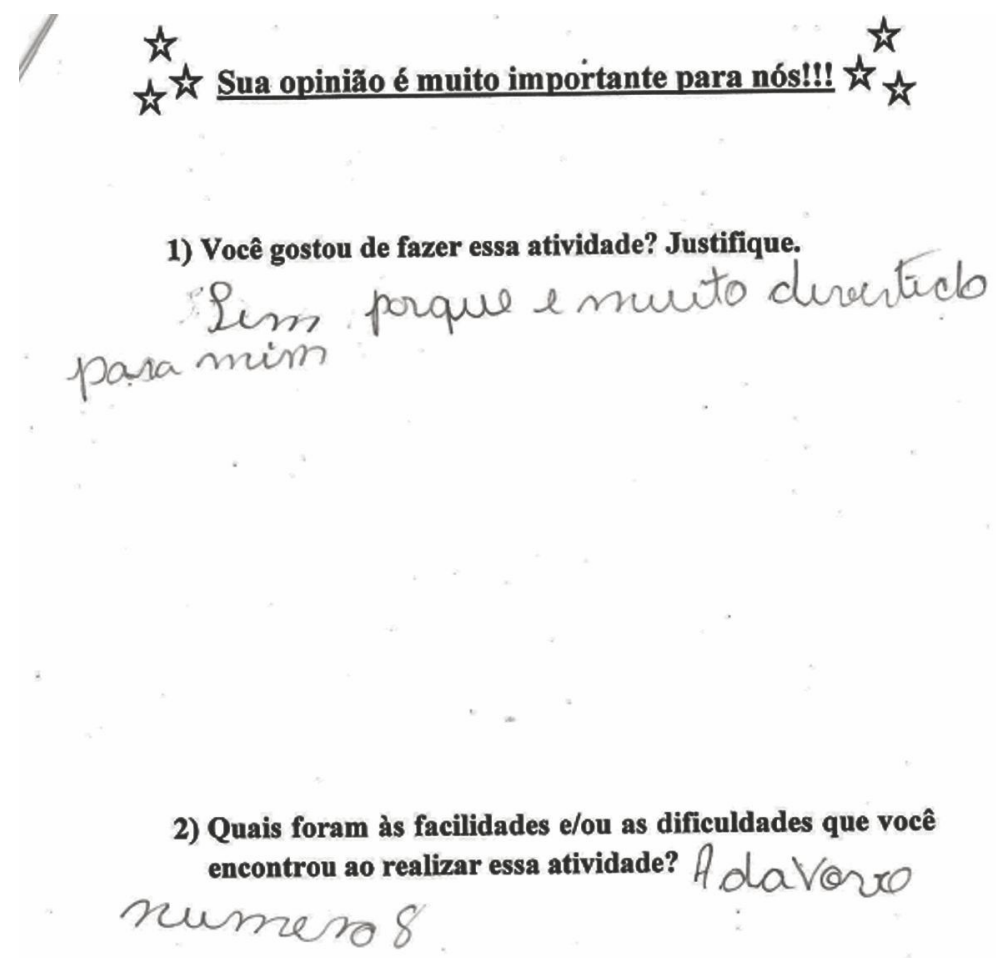

Fonte: Acervo das autoras.

Em um contexto geral, as pesquisadoras avaliaram a lista de exercícios como inadequada, considerando as dificuldades que os estudantes apresentaram para resolver os problemas matemáticos. Entretanto, todas as crianças afirmaram que o trabalho realizado foi positivo, conforme se pode ver, por exemplo, nas Figuras 8 e 9.

A partir da lista de exercícios, foi possível formular algumas perguntas fundamentais para a nossa pesquisa: como tem se organizado a relação entre professores e crianças nos espaçostempos da sala de aula e da escola? O que a escola e o aprendizado em matemática representam para as crianças e para as professoras? O que sabemos sobre essas crianças, suas vidas e seus interesses? Sabemos que os desdobramentos das pesquisas sobre as infâncias e as crianças nos espaços-tempos da escola dirigem-se para a escuta das crianças, porém escutá-las não é apenas ouvi-las, mas sim estar disposto a respeitá-las como sujeitos plenos de direitos (SARMENTO, 2005; CORSARO, 2005). Consideramos que a participação das crianças na construção das atividades sociais e escolares é de fundamental importância, já que consiste em uma forma de garantir o direito a se manifestarem por meio de opiniões e/ou ideias. De acordo com as disposições do Art. 2, da Convenção Sobre os Direitos da Criança, aprovado em 1959, o direito à participação se aplica a cada criança,

[...] independientemente de la raza, el color, el sexo, el idioma, la religión, la opinión política o de otra índole, el origen acional, étnico o social, la posición económica, 
los impedimentos físicos, el nacimiento o cualquier otra condición del niño. (UNICEF, 2008, p. 11).

Após avaliarmos a lista de exercícios matemáticos como inadequada aos nossos propósitos, optamos por produzir, no dia 27 de novembro de 2011, uma atividade lúdica: um bingo matemático, envolvendo a resolução de operações de adição e subtração, sendo que nas cartelas constavam os resultados das operações em questão. Na organização deste jogo, optamos por dividir os alunos em grupos de cinco crianças e cada grupo receberia uma cartela constando números diferentes. Sorteávamos uma operação e a escrevíamos no quadro negro; os grupos punham-se a resolvê-la, conversando entre si para saber o resultado e depois confirmá-lo na cartela. Tal processo foi repetido até que um dos grupos marcasse todos os números de sua cartela.

A duração desse trabalho foi menor do que a anterior, em torno de 50 minutos, pois as operações envolveram apenas soma e subtração e, rapidamente, as crianças resolveram o que Ihes fora pedido. Outro ponto que contribuiu para que essa atividade se dinamizasse e envolvesse todas as crianças em sua realização foi a organização do trabalho em grupos de alunos.

As crianças participaram do jogo, fizeram as operações com animação e curiosidade, pois queriam saber se cada resultado estava, ou não, na sua cartela. Outro ponto positivo observado foi o envolvimento das crianças com a atividade proposta, entre si e com as pesquisadoras, prevalecendo um clima lúdico, de interesse, alegria, disposição e envolvimento com a atividade. Nesse processo, destacou-se a organização que as crianças estabeleceram nos grupos. A vontade de fazer e acertar as operações foram implicações importantes nesse exercício, que contribuiu o entendimento sobre como podemos construir uma escola com as crianças e não simplesmente para elas.
A avaliação das pesquisadoras sobre os resultados alcançados após a realização do bingo foi positiva, pois as crianças se envolveram em todo o processo e, com isso, pudemos observar como elas aprendem conteúdos escolares, inclusive matemática, e como se dá o comprometimento com as atividades e com as pessoas noespaço-tempo da escola. Constatamos que as crianças, normalmente, querem e podem aprender, sobretudo quando podem trabalhar coletivamente em uma atividade lúdica.

A partir dos resultados apresentados, podemos dizer que o empenho das crianças em compreender as operações matemáticas, desenvolvê-las, interpretar as situaçõesproblema, trabalhar junto com os colegas e a vontade de aprender foram algumas das características que mais se destacaram no bingo promovido.

O trabalho indicou que, para promovermos o ensino-aprendizado na escola, poderíamos abrir mão da posição tradicional, que envolve levar, para o ambiente escolar, atividades preconizadas por uma cultura conservadora e adultocêntrica, confirmada por livros e materiais didáticos concertados por uma concepção bancária de educação. Para que isso aconteça, podemos ousar e experimentar diferentes papéis: professor que aprende para ensinar; estudantes que, envolvidos com a atividade proposta, ensinam ao professor o que é ser criança e as diferenças; pesquisadoras que se desafiam a aprender com professores e, principalmente, com as crianças sobre o cotidiano escolar. Pensamos que o sentido do ousar, nesse caso, está plenamente interligado às palavras sensíveis de Paulo Freire (2002, p. 10):

É preciso ousar para jamais dicotomizar o cognitivo do emocional. É preciso ousar para não ficar ou permanecer ensinando por longo tempo nas condições que conhecemos, mal pagos, desrespeitados e resistindo ao risco de cair vencidos pelo cinismo. É preciso ousar, aprender a ousar, para dizer não à 
burocratização da mente a que nos expomos diariamente. É preciso ousar para continuar quando às vezes se pode deixar de fazê-lo, com vantagens materiais.

A ousadia é uma opção que muitos educadores podem fazer na trajetória de aprender e ensinar, principalmente quando se trata da ousadia de aprender com as crianças e abandonar o lugar comum do professor que tudo sabe. No nosso caso, como pesquisadoras, nossa modesta ousadia tem sido a de continuar a pesquisa tentando compreender e nos relacionar com crianças vistas como sujeitos de direitos, usuárias, produtoras e ressignificadoras da cultura.

De maneira geral, podemos dizer que o trabalho realizado nos permitiu concluir, primeiramente, que as professoras desconheciam muitos aspectos do jeito de ser dos estudantes com os quais conviviam. Sendo assim, elas nos orientaram a trabalhar com aspectos da matemática, cujo aprendizado era difícil para as crianças. Entre as professoras é muito forte a repetição de um conteúdo para que as crianças o aprendam, por isso é muito valorizada a ideia de reforço da aprendizagem. Ao apresentar a lista de exercícios, repetimos o conceito e a prática do reforço. Fizemos o mesmo que a escola costuma fazer, tentando, no entanto, conhecer os estudantes e suas relações com o conhecimento. Formulamos exercícios que as crianças não compreendiam total ou parcialmente e, com isso, evidenciamos o que não sabiam, mas também aprendemos sobre práticas equivocadas de ensinar. Tal atividade só poderia mostrar ou confirmar o que os alunos não sabiam, pois se centrou apenas nos conteúdos escolares. Confirmou-se, para nós, que o interesse maior na pesquisa é conhecer as crianças e seus jeitos de aprender. Já na primeira atividade, com a lista de exercícios, formulada para ser resolvida individualmente, percebemos que as crianças necessitavam de interação umas com as outras durante o trabalho. Tais conversas consistiam em simples checagem de resultados finais de um ou outro exercício ou na observação e reprodução de estratégias utilizadas por colegas na resolução dos exercícios para repetilas e até a realização conjunta de trabalho. A conversa e o relacionamento entre as crianças são, em geral, muito desvalorizados e incompreendidos pela escola, que privilegia o silêncio e o individualismo. Por isso, com o bingo, incentivamos as crianças a se agruparem e a conversarem entre si para a realização do trabalho proposto. Constatamos, então, que o aprender requer o outro como parceiro, sendo que este companheiro de aprendizado pode ser a própria criança ou um adulto (VYGOTSKY, 1989).

Porfim, a avaliação daspesquisadorassobre os resultados alcançados após a realização do bingo foi positiva, pois as crianças se envolveram em todo o processo e, com isso, pudemos observar como elas podem aprende e como pode se dar o comprometimento com as atividades e com as pessoas no espaço-tempo da escola.

Constatamos que as crianças normalmente querem e podem aprender, sobretudo quando trabalham em conjunto e em atividades lúdicas significativas de muitas maneiras para elas (HUIZINGA, 2001), nas quais os adultos, embora responsáveis pelo processo de ensinar, são também parceiros no aprendizado. Com isso, a pesquisa deixou de enfatizar conteúdos escolares e se reorientou para produzir atividades artísticas com as crianças, momentos em que elas se constituem como sujeitos plenos de aprendizado. Passamos a produzir atividades que envolvam a imaginação infantil, base do aprendizado humano, enfatizando e conhecendo a criatividade, as diferenças e jeitos de aprender infantis. 


\section{Referências}

CORSARO, W. A reprodução interpretativa no brincar ao "faz de conta" das crianças. Educação, Sociedade \& Culturas, Porto, n. 17, p. 113-134, 2005.

FREIRE, P. Pedagogia da autonomia: saberes necessários á prática educativa. 37. ed. São Paulo: Paz e Terra, 2008.

FREIRE, P. Professora sim, tia não: cartas a quem ousa ensinar. 11. ed. São Paulo: Olhos d'Água, 2002.

HUIZINGA, J. Homo ludens. 5. ed. Tradução de J. P. Monteiro. São Paulo: Perspectiva. 2001.

SARMENTO. M. J. Gerações e alteridade: interrogações a partir da sociologia da infância. Educação e Sociedade, Campinas, 2005, v. 26, n. 91, p. 361-378, maio/ago. 2005.

UNICEF. A convenção sobre os direitos das crianças. 2008. Disponível em: < http://www.unicef. org/sowc98/sowc98.pdf> Acesso em: 15 mar. 2012.

VYGOTSKY, L. S. A formação social da mente. 3. ed. Tradução de J. C. Neto. São Paulo: Martins Fontes, 1989.

Submetido em 23 de fevereiro de 2013.

Aprovado em 17 de junho de 2013. 